\title{
Gilligan: a voice for nursing?
}

\author{
Jean Harbison Glasgow South College, College of Nursing, Glasgow
}

\section{Author's abstract}

The current reform of nursing education is resulting in major changes in the curricula of colleges of nursing. For the first time, ethical and moral issues are being seen as an important theme underpinning the entire course.

The moral theorist with whose work most nurse teachers are acquainted is Kohlberg. In this paper, it is suggested that his work, and the conventions of morality which he exemplifies, may not be the most appropriate from which to address the moral issues facing the nurse.

The author suggests that the work of Carol Gilligan of Harvard university is of great significance, not only for nurses involved in the teaching of ethics, but for all nurses. Gilligan's emphasis on caring and relationships accords with the common experience of the nurse, and echoes the current revival of interest within nursing in examining, and valuing, the phenomenon of caring.

There is growing interest among nurse educators in developing the critical-thinking skills of students $(1,2,3,4,5)$. This may in part be due to the influence of Schon's views on the role of critical reflection in the development of a professional practitioner $(6,7)$. There is increasing interest also in preparing nurses to consider the ethical and moral implications of the situations with which they are daily faced $(8,9,10)$. Critical scrutiny of practice, according to Schon, demands a sound knowledge-base from which to reflect. McInerny challenges health-care professionals to be as familiar with as many ethical theories as possible in order to be able critically to scrutinise moral thinking (11). The theory of moral development usually considered by nurse teachers (12) is that of Kohlberg (13) whose work is paralleled by Piaget (14) in the field of cognitive development.

\section{Kohlberg's theory of moral development}

Kohlberg's work is based on Kant's model of moral autonomy and reason. The moral agent is characterised as one who objectively analyses moral dilemmas and

\section{Key words}

Nursing; nursing education; nursing ethics; moral development; moral decision-making; ethical decisionmaking. uses rules and principles to make a rational justification of choices. High values are placed on individual autonomy, personal liberty and human rights. The problems of morality are defined in terms of conflicts: solutions are reached by ordering rights. This perspective has been termed one of justice (15), and it is one which underlies the framework of rules and principles which dominates thinking on biomedical ethics. Kohlberg, in his research on adolescents claims to distinguish clear stages in moral development: preconventional: where responses to moral dilemmas are absolute and egocentric; conventional: where responses are related to societal, moral and legal codes, and post-conventional: where universal moral principles inform the response, regardless of societal codes. Operational thought, as defined by Piaget, is a prerequisite (though not a guarantee) of the higher stages of moral response. Kohlberg's research was carried out on adolescent boys, and appeared to be applicable across several cultures.

However, the applicability of this theory to adults has been queried by Murphy and Gilligan (16). In addition, Riegel's theory of dialectical operational thought claims that adults are capable of further cognitive development, and therefore by implication, moral reasoning development (17). The applicability of Kohlberg's theory to women has also been queried by Gilligan (15). It has been suggested that the work of Harvard educator Carol Gilligan is deserving of consideration by nurses (18). Study of Gilligan's writings indicates that her ideas on moral development are more relevant to the moral experience of the nurse than those of Kohlberg.

\section{Gilligan's work on moral development $(15,16,19,20,21)$}

Our moral judgements reflect our understanding of ourselves and of society. They are derived from our experience of human relationships. Within the parent/ child relationship, according to Gilligan, we experience both attachment and inequality. We therefore develop from this experience ideas about care and justice. It is Gilligan's contention that since the experience of girls is different from boys, it is logical that they will develop different understandings of self 
and society and, therefore, different ways of viewing moral issues.

Gilligan therefore challenges Kohlberg's moral development theory on the grounds that the traditional assumptions of moral philosophy fail to reflect women's experience. Gilligan suggests that, where the moral reasoning of girls would be defined by Kohlberg as being deficient in moral development, this is due to the different emphasis placed by them on maintaining and strengthening relationships. The perspective women have on morality, which Kohlberg classifies as deviance, is understood by Gilligan to reflect women's social and moral understanding and to be equally valid, rather than deviant.

Central to Gilligan's thinking is the meaning of responsibility. Conventionally it carries the meaning of commitment to obligations. Gilligan would extend that definition to include also responsiveness within relationships. Common understanding is that responsibility means making a commitment and sticking to it. In Gilligan's extended understanding, it means also being aware of others and their feelings; taking charge of oneself by looking at others and their needs, and taking the initiative. This construction of responsibility implies that the moral agent acts responsively in relationships. A moral agent therefore is characterised as one who responds to need and demonstrates a consideration of care and responsibility in relationships. In this understanding, morality is seen as grounded in a perspective of caring. It is suggested that it is from this caring perspective that females view moral and ethical decision-making.

There are therefore two (at least) possible perspectives from which to make moral judgements: the conventional perspective, that which Gilligan terms 'justice', and women's perspective, termed that of 'care'. Gilligan claims that the two moral 'voices' can be clearly distinguished in the way people frame and resolve moral problems and evaluate choices. The conventional voice speaks of equality, reciprocity, justice and rights. These terms imply individual separation, hierarchical and contractual relationships, and the alternatives of constraint or co-operation. The female voice speaks of connection, not hurting, care and response. These terms imply interdependent individuals, and networks of relationships created and maintained by attention and response. The two voices are seen to represent predominant, but not exclusive, patterns of thinking in any individual.

The participants in Gilligan's research were not exclusively female, and she is careful to state that she does not intend to create disagreement between, or claim superiority for, either sex: her claim is simply that the sexes' different experience leads to the adoption of a different perspective on morality. Nor does she claim that a caring perspective is exclusive to women, rather that any individual may display either of these voices, but women have a stronger tendency to speak with the latter. The two perspectives are not completely opposed to each other: justice is not necessarily uncaring, and caring is not necessarily unjust. The two views of morality are therefore complementary rather than opposed. Although it is impossible to view a moral problem from both perspectives simultaneously, it is possible to attempt a shift in perspective. This may mean a re-definition of the problem.

As Blum (22) points out, a dominant concept in western morality has been that of what he terms 'impartialism', or what Gilligan would call 'detachment'. The cult of the individual in our society has traditionally placed a value on detachment. (As Gilligan points out, Sigmund Freud claimed to detect a failure of moral development in women as characterised by a reluctance to develop an attitude of detachment.) The self, though placed in the context of relationships, is defined in terms of separation. The capacity for engagement with others is observed during development, but is not well represented in accounts of human development. Gilligan suggests that this may be because it is at odds with the current concepts of self. In Gilligan's vision, dependence is assumed to be part of the human condition; being dependent is not regarded as being helpless and powerless, but simply being convinced that people have an effect upon each other, and recognising that interdependence empowers both. The reference for moral judgemen 8 now becomes, not oneself, but the relationship between the self and others.

Therefore, although from the justice perspective detachment is an advantage, allowing objective decision without passion; from the caring perspective, detachment in fact becomes a moral problem. The first perspective seeks to reconcile two separate positions; the second seeks to understand the relationship between two connected positions. From the first perspective, the ideal to be attained is perfection, against which the self is measured; from the second, the ideal is care, against which the worth of one's actions is measured.

\section{The relevance of Gilligan's work to nursing}

Gilligan's emphasis on caring and relationships accords with nurses' common experience, and is echoed in the renewed interest in nursing literature in the phenomenon of caring since the mid 1970s $(23,24,25$, 26). Patricia Benner, in her important descriptive study of nursing, as practised by experienced nurses, identifies the central place which caring, that is 'a committed, involved stance in nursing practice', holds in their practice (27). The importance of caring as the profession's raison d'etre is further affirmed by Benner and Wrubel (28). The basic activities of caring are being there, listening, being willing to help and able to understand. These take on a moral dimension, reflecting the imperatives to pay attention, and not turn away from need. For example, one nurse might discern, in casual conversation with a patient, a disguised plea for help, where another nurse might $\bar{q}$ not. From Gilligan's perspective, the sensitivity and 
attentiveness to another's need demonstrated by the first nurse are moral qualities.

Gilligan's gender-related theory may also be particularly appropriate for nurses, given the female domination of the profession and provides a defence for those attributes of caring and sharing which traditionally have not been highly valued by dominant ideology. Kurtz and Wang (29) point out that nurses are caught in the dilemma of being asked to provide care by a society which does not value caring; or more specifically perhaps, does not value those attributes informing the moral perspective described above by Gilligan.

In nurse education the practice of providing clinical simulation or scenarios is becoming common $(30,31$, 32). This gives students the opportunity to practise decision-making skills under supervision in the classroom prior to clinical practice. The writer recently was in discussion with a group of nursing students considering a situation where the moral choice was whether or not to tell the truth. The ethical principles of autonomy, beneficence and non-maleficence were addressed in relation to the situation. Characteristic of student comments were 'It depends ...', 'I'd have to know the patient', and 'Your decision would depend on the relationship you had with the patient and his relatives - and also with the doctors'. The writer would suggest that this unwillingness to make a definite decision reflects very clearly, neither a lack of knowledge, nor a deficiency in moral thinking, but a perspective from which moral imperatives are contextual and not categorical. The focus, not on the concerned parties' rights, but on the network of relationships between them, accords exactly with Gilligan's findings in her work on the moral thinking of women. Gilligan's understanding of 'the relationship between a perspective of care and the traditional perspective of justice provides a paradigm for a cooperative and complementary relationship between the sometimes conflicting positions of nursing and medicine in moral decision-making' (18).

Nurses have traditionally found difficulty in defining nursing, and distinguishing it as an entity different from, but closely related to, other health-care disciplines. It has been suggested that the ethic of caring may well be the core of nursing, which separates it from other disciplines (29). Current thinking in biomedical ethics does not appear entirely to address the moral experience of the nurse, or form a complete ethic of care. Gilligan's work does not reflect the framework of rules and principles dominating thinking on biomedical ethics which influences the work of the nurse. Neither does her work constitute an ethical theory, and therefore it cannot provide specific behavioural guidelines. It does, however, affirm that the nursing experience of caring is a moral experience; and furthermore affirms its value. It is therefore suggested that Gilligan's ethic of care is at the very least deserving of consideration by the next generation of nurses and those who teach them. fean Harbison, BA, RGN, SCM, RCNT, RNT, is a Nurse Teacher at Glasgow South College of Nursing, Glasgow.

\section{References}

(1) Clarke M. Action and reflection: practice and theory in nursing. Fournal of advanced nursing 1986; 11, 1: 3-11.

(2) Gordon $M$. The nurse as a thinking practitioner. In: Hannah K J, Reimer M, Mills W C, Letourneau S, eds. Clinical judgement and decision making: the future with nursing diagnosis. New York: John Wiley and Sons Inc, 1987: 8-17.

(3) Burnard P. Developing critical ability in nurse education. Nurse education today 1989; 9: 271-275.

(4) Burnard P. Critical awareness in nurse education. Nursing standard 1990; 4, 30: 32-34.

(5) Powell J H. The reflective practitioner in nursing. Fournal of advanced nursing 1989; 14, 10: 824-832.

(6) Schon D A. The reflective practitioner. New York: Basic Books, 1983.

(7) Schon D A. Educating the reflective practitioner. San Francisco: Jossey-Bass Publishers, 1987.

(8) Melia K M. Everyday nursing ethics. Basingstoke: MacMillan, 1989.

(9) Rowson R H. An introduction to ethics for nurses. Harrow: Scutari, 1990.

(10) Tschudin V. Ethics in nursing: the caring relationship. London: Heinemann, 1986.

(11) McInerny W F. Understanding moral issues in health care - seven essential ideas. Fournal of professional nursing 1987; 3: 268-277.

(12) Frisch N C. Value analysis: a method of teaching ethics and promoting the moral development of students. Fournal of nursing education 1987; 26, 8: 328-332.

(13) Kohlberg L, Levine C, Hewer A. Moral stages: a current formulation and a response to critics. Basel and New York: Karger, 1983.

(14) Piaget J. The moral judgement of the child. London: Routledge and Kegan Paul, 1932/68.

(15) Gilligan C. In a different voice. Cambridge, Mass: Harvard University Press, 1982.

(16) Murphy M, Gilligan C. Moral development in late adolescence and adulthood. Human development 1980; 23: 77-104.

(17) Allman P. The nature and process of adult development. In: Tight M, ed. Education for adults: vol 1: adult learning and education. London: Croom Helm/Open University, 1983: 107-123.

(18) Cooper M C. Gilligan's different voice-a perspective for nursing. Fournal of professional nursing 1989; 5, 1: 10-16.

(19) Gilligan C. Remapping the moral domain: new images of the self in relationship. In: Heller $T C$, Sosna $M$, Wellbery D E, ed. Reconstructing individualism: autonomy, individuality and the self in western thought. Stanford, Ca: Stanford University, 1986: 237-252.

(20) Gilligan C. Moral development. In: Chickering A W, ed. The modern American college. San Francisco: Jossey-Bass Publishers, 1981: 139-157.

(21) Gilligan C. In a different voice: women's conceptions of self and morality. Harvard educational review 1977; 74, 4: 481-517.

(22) Blum L A. Gilligan and Kohlberg: implications for moral theory. Ethics 1988; 98: 472-491.

(23) Bevis O, Watson J. Toward a caring curriculum: a new pedagogy for nursing. New York: National League for Nursing, 1989. 
(24) Watson J. Nursing: human science and human care. Norwalk, Conn: Appleton-Century Crofts, 1985.

(25) Leininger $M$, Watson J, eds. The caring imperative in education. New York: National League for Nursing, 1990.

(26) Harrison L. Maintaining the ethic of caring in nursing. Fournal of advanced nursing 1990; 15: 125-127.

(27) Benner P. From novice to expert: excellence and power in clinical nursing practice. Menlo Park, Ca: AddisonWesley, 1984: 170.

(28) Benner P, Wrubel J. The primacy of caring: stress and coping in health and illness. Reading, Mass: Addison-
Wesley, 1989.

(29) Kurtz R J, Wang J. The caring ethic: more than kindness, the core of nursing science. Nursing forum 1991; 26, 1: 4-8.

(30) Dooling S L. Designing computer simulations. Computers in nursing 1987; 3, 3: 113-116.

(31) Klaessens E L. Exploring use of computer simulation to teach critical decision making skills to paediatric nursing students. Fournal of paediatric nursing 1988; 3, 3: 202206.

(32) Thiele J E, Baldwin J H. A simulated practice environment. Computers in nursing 1985; 5, 6: 219-224. 